The capacity for health promotion survey

\author{
Annick Maujean $^{\text {a }}$ \\ Elizabeth Kendall ${ }^{\mathrm{a}}$ \\ Carolyn Ehrlich $^{\text {a }}$ \\ Steve Kisely ${ }^{b}$
}

\footnotetext{
${ }^{a}$ Centre for National Research on Disability and Rehabilitation Medicine (CONROD), Griffith Health Institute, Griffith University, Meadowbrook, Australia

${ }^{\mathrm{b}}$ School of Population Health, University of Queensland, Herston, QLD, Australia
}

Correspondence should be addressed to:

Annick Maujean, $\mathrm{PhD}$

Centre for National Research on Disability Rehabilitation Medicine (CONROD), Griffith Health Institute, Griffith University, Meadowbrook QLD 4131, Australia

Telephone: +61 (07) 33821046

Facsimile: +61 (07) 33821414

Email: a.maujean@griffith.edu.au

Key words: Health promotion, mental health, physical health, reliability, validity

Running title: Capacity for health promotion 


\title{
The Capacity for Health Promotion Survey
}

\begin{abstract}
Objective: To develop and examine the psychometric properties of the Capacity for Health Promotion Survey designed to assess the practice of health promotion in the area of severe mental illness.
\end{abstract}

Method: Seven hundred and eighty-five health professionals in Queensland, Australia completed the survey. A principal component analysis was used to assess the factor structure of the scale and investigations of internal consistency, inter-item correlation and itemdiscriminant validity were conducted to establish the reliability and validity of the survey.

Results: The final survey is a 22-item scale comprising five subscales: Beliefs about Behaviour Change, Intention to Promote Health, Health Promotion Skills, Effectiveness of Health Promotion, and Health Promoting Norms. The survey demonstrated satisfactory internal consistency for the five subscales. Items were more strongly correlated within their own subscales than with other subscales, providing evidence of discriminant validity.

Conclusion: The Capacity for Health Promotion Survey is a psychometrically sound measure to assess the practice of health promotion in the area of severe mental illness. 


\section{Introduction}

The risk of mortality is over $70 \%$ higher among people with severe mental illness (SMI) than in the general population, even after adjusting for socio-economic status and behavioural risk factors [1]. For those with SMI, death is 10 times more likely to be associated with chronic disease than with suicide [2]. Mortality from chronic physical disorders is excessive among those with SMI, yet it receives far less attention in this group than in the general population. A recent systematic review identified elevated rates of death in people with SMI for all causes apart from cerebrovascular diseases [3]. Further, these death rates have increased over time, suggesting that people with SMI have not shared in the overall health improvements that have been experienced by the general community [4].

Despite improvements in the early detection of psychosis, and the implementation of community-based mental health services, the Australian health system fails to provide optimal physical care for those with SMI [5]. There is clearly an urgent need to ensure that people with SMI receive the best-available physical and oral health care, timely diagnoses and appropriate preventative interventions, particularly given the cost and difficulty of managing complex conditions in addition to SMI. In the case of cancer, for instance, the incidence among psychiatric patients is no higher than that of the general population, but the mortality rate is higher [4]. Oral health is a particularly neglected area of physical comorbidity in people with SMI, with the result that they are over three times as likely to have lost all their teeth compared to people in the general community of similar age [5]. A likely explanation for such poor health outcomes is that physical ill-health goes unrecognised among those with SMI [6]. They may be less likely to report a medical complaint and have more difficulty interpreting physical symptoms, or distinguishing them from symptoms of their mental illness [7]. They may also be less able to problem-solve and care for themselves. Even if physical health problems are diagnosed, this population may be less likely to receive 
or adhere to adequate treatment, resulting in worse prognoses [8]. This lack of physical care is paradoxical, given that physician consultation rates are generally high among those with SMI [9]. However, in several studies, patients with SMI were unlikely to have had a preventative physical examination (eg. weight, blood pressure) or to be assessed and treated for a range of diseases $[10,11]$. Thus, delays in initial presentation may lead to a more advanced disease state at diagnosis and, therefore, less likelihood of successful treatment. People with SMI are also less likely to receive appropriate preventative medications, such as betablockers and statins, on discharge following myocardial infarction [12]. Thus, even when comorbid physical illnesses are detected and treated within the health system, people with SMI are not afforded the same level of ongoing preventative treatment as the general community.

Health professionals who have contact with the SMI population in the course of their psychiatric care are in a unique position to promote physical and oral health, but often fail to do so. Each year, an enormous amount of funding and time is put into the development and dissemination of guidelines to facilitate practice that improves the physical quality of life for people with SMI. However, it is extremely difficult to facilitate the translation of these guidelines into effective health promotion and disease prevention practices among clinical health professionals. In fact, it is well documented that the translation of preventative knowledge into practice is usually hindered by the limited capacity of health professionals, such as time and resources, training, incentives, feedback, or systems to support translation [13]. As a result, important prevention opportunities are lost and the SMI mortality gap remains a challenge for equitable health in Australia.Building the capacity of health professionals has been shown to sustain effective health promotion [14]. Capacity building relates to individuals' knowledge, skills, commitment, motivation, intention and resources (time, financial and infrastructure) to conduct health promotion [15]. However, understanding 
capacity also requires examination of organisational and social factors that influence practice, such as organisational commitment, culture, structures (e.g., policies), normative influences and group processes to support health promotion [16].

Currently, few measures exist to measure health promotion capacity and none focus on the application of health promotion in complex populations, such as SMI. One useful but lengthy survey instrument is the Health Promotion Capacity Checklist [15]. This instrument has not been validated, although it does attempt to assess a broad model of capacity and is useful for planning health promotion initiatives. Other validated measures focus on small components of capacity, such as leadership for health promotion [17], synergy in health promotion partnerships [18], individual and organizational infrastructure [19], will to promote health [20], and community capacity for prevention [21]. Although capacity is a contested concept [22], the need to assess the strengths and weaknesses of national health promotion ability has been recognized internationally [23]. Without some understanding of health promotion capacity, the readiness to address rising health challenges is questionable.

The purpose of the current paper is to explore the health promotion and disease prevention capacity of those who deliver services to people with SMI in Queensland, Australia. Specifically, this paper describes the development of a short questionnaire to assess capacity in this area. The Capacity for Health Promotion Survey was developed and tested in a diverse sample of health providers from the public health system, primary health care and the non-government sector.

\section{Method}

\subsection{Participants}

A total of 785 participants completed the survey during a three-month period in 2011. The demographic characteristics of these participants are presented in Table 1. Participants all worked in Queensland, Australia in the government and non-government systems and 
included general practitioners, nurses, allied health professionals and other health workers who provided services to individuals suffering from a severe SMI. The majority of participants had a nursing background (43.9\%). The age of participants ranged from 18 to 69 years with an average of 41.92 years $(S D=11.18$ years). A greater number of females $(77.3 \%)$ than males $(21.3 \%)$ completed the survey, which is an accurate reflection of the health professional workforce in Australia. Eighty-one percent of the respondents had a university degree, as would be expected, and $41.4 \%$ had received over 40 hours of specific training in health promotion (e.g., short courses or online programs). Over $70 \%$ of the participants were employed full-time when they completed the survey. Given that participants worked across several contexts that differed in the level of SMI specialisation (i.e., public mental health services versus community general practice), there was large diversity in the amount of direct contact with SMI. However, approximately one third of the participants reported providing more than 20 consultations per month to people with SMI, suggesting a relatively high level of exposure.

Insert Table 1 about here

\subsection{Measures}

The Capacity in Health Promotion Survey is a self-report measure developed to assess the relevant domains of health promotion capacity (i.e., skills, professional norms, beliefs about behavioural change, intention to promote health, and perceived effectiveness of health promotion). A pool of 22 items was generated following discussions with a panel of experts in health promotion and SMI, a review of the literature, and examination of existing health promotion measures (e.g., 24,25,26,15). Where items were drawn from existing scales that assessed one of the selected domains of capacity, they were modified to reflect the focus of 
this survey on SMI. The items were reviewed and refined by the panel to improve clarity, relevance and comprehensiveness. A 7-point Likert scale was used with categories ranging from 1 = "strongly disagree" to 7 = "strongly agree" or 1 = "low" to 7 = "high" depending on the wording of the item.

\subsection{Procedure}

The final Capacity in Health Promotion Survey was distributed to health professionals who worked in public mental health services, primary care and the non-government mental health sector in Queensland. It was sent via emails from key leaders in each sector to all relevant employees (i.e., those considered likely to have contact with patients who have been diagnosed with SMI or involved in some aspect of service delivery to people with SMI).

Recipients of the email were requested to complete the survey and return it anonymously to the university. Ethical clearance for the study was granted by the Griffith University Human Research Ethics Committee and by the Queensland Health Metro South Human Research Ethics Committee.

\subsection{Statistical Analyses}

Statistical analyses were performed using the Statistical Package for Social Sciences, Version 21 for Windows [27]. A principal component analysis with varimax rotation was performed to explore the factor structure of the scale. To ensure that participant' responses were distributed across the rating scale (i.e., 1 to 7), floor and ceiling effects were assessed according to the number of respondents scoring the minimum or maximum scores. A cut-off of $20 \%$ was considered acceptable [28]. Spearman's bivariate correlations were used to examine the relationships between the subscales. Cronbach's alpha coefficient was used to calculate the internal consistency of the subscales, with alpha coefficients $>.9$ considered "Excellent", > .8 "Good", > .7 “Acceptable" [29]. Scaling assumptions were checked by means of item-total correlation corrected for overlapping (each relevant item is removed from 
its domain for correlation), values of .30 or higher were considered appropriate. Inter-item correlation and item-discriminant validity were examined to further establish the reliability and validity of the survey.

\section{Results}

A principal component analysis (PCA) with varimax rotation was performed on the 22 items of the Capacity for Health Promotion Survey. Kaiser-Meyer Olkin measure of sampling adequacy was .88 and Bartlett's test of Sphericity was significant, $p<.001$, supporting the factorability of the correlation matrix. The PCA generated five components with eigenvalues exceeding 1 , accounting for $72.59 \%$ of variance. Communality estimates ranged from .48 to .92 . As shown in Table 2, all 22 items had loadings of .40 and above and all items loaded exclusively on their respective component.

Insert Table 2 about here

Examination of the item content for the five components (Table 2) indicated that the first component comprised five items related to beliefs about the ease with which people with SMI could be encouraged to modify risky health behaviours (Beliefs about Healthy Behaviour Change). Seven items on the second component represented health professionals' intention to advise people with SMI on a range of health issues such as obesity and sexual health (Intention to Promote Health). The third component consisted of three items pertaining to the perceived effectiveness of promoting health among people with SMI in various areas such as healthy lifestyle and quality use of medicine (Perceived Effectiveness of Health Promotion). Four items that loaded on the fourth component represented health professionals' skills in engaging in health promotion (Health Promotion Skills). Finally, the fifth component consisted of three items relating to broader influences on health professionals 
attitudes towards the inclusion of health promotion in their practice (Health Promoting Norms). All 22 items were retained for the final version of the Survey.

Scale scores were computed as the mean score for each subscale. Each of the subscales showed acceptable levels of endorsement by the participants. With the exception of the Effectiveness of Health Promotion subscale, no floor and ceiling effects were observed (i.e., the percentages of minimum or maximum scores on all other subscales were well below the cut-off of 20\%), indicating that participants' scores were well distributed across the rating scale. The means for the five subscales ranged from 4.48 (Health Promotion Skills) to 5.82 (Perceived Effectiveness of Health Promotion). Although all subscales were negatively skewed, this was unlikely to create substantive differences in the analysis with reasonably large samples of 200 or more cases [30]. Further, comparable skewness in the same direction across sub-scales minimizes the importance of the issue. The percentage of missing data for each subscale ranged from $4.1 \%$ to $15.4 \%$. The highest rate of missing data was observed for the 'Intention to Promote Health' (15.4\%) and 'Health Promoting Norms' (13.0\%) subscales.

\subsection{Inter-domain correlations}

Spearman's correlation coefficient was used to examine the strength of the relationships between the five subscales. As shown in Table 3, the correlations between the subscales were low to moderate ranging from .16 to .48 . The closest association was observed for the 'Perceived Effectiveness of Health Promotion' and 'Beliefs about Behaviour Change' subscales $(\mathrm{r}=.48)$, which is not surprising given the likely relationship between these constructs. The weakest association was obtained between the 'Beliefs about Behaviour Change' and 'Health Promoting Norms' subscales $(r=.16)$. This finding confirms that normative influences found in particular professional fields may have little to do with the individual beliefs of practitioners. 
Insert Table 3 about here

\subsection{Internal consistency}

The internal consistency of the items was calculated using Cronbach's alpha coefficients. As shown in Table 4, Cronbach's alpha coefficients for the five subscales were moderate to high, ranging from .65 to .97 . Although Cronbach's alpha coefficients were slightly below the cut-off of .70 for the Health Promoting Norms subscale (.65), it was considered acceptable. All corrected item-total correlations attained values higher than the criterion (.30), indicating that all items were adequately related to other items on their respective subscales.

\subsection{Item-discriminant validity}

In order to assess item-discriminant validity, items that make up a subscale were correlated with items of other subscales which represent and assess different constructs. Item-discriminant validity is demonstrated when an item correlates higher with its own scale than with other scales. Although there was some overlap between items belonging to different subscales (compare the inter-item correlations and the item-discriminant validity columns in Table 4), these were minor.

\section{Insert Table 4 about here}

Within the subscales, a low correlation was found between two items on the Health Promotion Skills subscale, namely Item 1 - "I feel properly trained to give health promotion advice to the general population" and Item 3 - "It is not difficult to counsel people with severe mental illness about an alternative lifestyle to promote their health" $(r=.26)$. This finding was not surprising given that the sample consisted of professionals who focused specifically in SMI and/or health promotion and those who had more generic training or 
experience. Similarly, on the Health Promoting Norms subscale there was a weak association between Item 1 - "Most professionals should include health promotion in their practice" and Item 3 - "The professional organisation I respect most would approve of including health promotion in my practice" $(r=.28)$. This finding is likely to reflect the fact that health promotion is not a standard component of practice despite the fact that it is generally regarded as desirable. All other inter-item correlations were satisfactory, with correlations of .40 and above. Furthermore, deleting these items did not substantially improve the internal consistency of the Health Promotion Skills (Crobach's alpha .81) and the Health Promoting Norms (Cronbach's alpha $=.65$ ) subscales. Therefore, all items for these two subscales were retained.

\section{Discussion}

The 5-factor structure described in this paper accounted for $72.59 \%$ of the total variance, indicating a reasonable solution. Factor loadings were relatively high and all items loaded exclusively and significantly on their respective components. The five components were labelled as Beliefs about Behaviour Change, Intention to Promote Health, Health Promotion Skills, Effectiveness of Health Promotion, and Health Promoting Norms. These components made sense conceptually and replicated the intended structure of the survey. Internal consistency for the five subscales was satisfactory and most items were more strongly correlated with their own subscales than with other subscales, providing evidence of discriminant validity. In addition, although not addressed in the current paper, our preliminary experience is that the 22-item questionnaire is feasible for use in mental health service settings and takes approximately 15 minutes to complete.

In brief, these findings indicate that the Capacity for Health Promotion Survey is a valid and reliable instrument to assess the practice of health promotion in the area of SMI. 
Further research is required to assess the temporal stability of the survey. In addition, a confirmatory factor analysis should be performed on a different sample of health professionals to confirm its underlying theoretical structure.

There are some limitations to the current study. Although we recruited a relatively large sample ( $\mathrm{n}=785)$, this was a self-selected group who represented only a small proportion of all potential participants. We cannot, therefore, exclude the possibility of selection bias with its consequent limitations to the generalisability of the scale beyond our sample and context (i.e., the context of health professionals working with people with SMI in Queensland, Australia).

Notwithstanding these limitations, this questionnaire may have international application, perhaps in relation to other at-risk populations (e.g., people with cognitive impairment, elderly, non-English speaking cultures) as a tool for identifying areas where professionals require support and training to facilitate physical health. Health promotion capacity has been notoriously difficult to measure for a range of reasons [31]. Capacity is an evolving concept that is developed slowly over time and with local nuances depending on how it is applied. Measures are designed to suit the specific needs of particular interventions, but little effort has been put into validating appropriate global measures of workforce capacity. Given that the need to map capacity to engage in health promotion has been continuously acknowledged at the level of individual workers, organizations and, indeed, entire countries [22], then a measure such as this could prove useful. Although pertaining specifically to the SMI population, our scale represents one of the few attempts to validate a broad measure of health promotion capacity with multiple domains and, therefore, provides an important contribution to this area. 


\section{References}

1. Hamer M, Stamatakis, E, Steptoe A. Psychiatric hospital admission, risk factors and allcause mortality. Arch Intern Med 2008; 168: 2474-9.

2. Author's own, 2005.

3. Saha S, Chant D, McGrath J. A systematic review of mortality in schizophrenia. Arch Gen Psychiatry 2007; 64:1123-31.

4. Author's own, 2008.

5. Author's own, 2011.

6. Goldman L S. Medical illness in patients with schizophrenia. J.Clin Psychiatry 1999; 60 Suppl 21: 10-15.

7. Auslander LA, Jeste DV. Perceptions of problems and needs for service among middleaged and elderly outpatients with schizophrenia and related psychotic disorders.Community Ment Health J 2002; 38: 391-402. 8. Roberts Roalfe A, Wilson S, Lester H. Physical health care of patients with schizophrenia in primary care: a comparative study. Fam Pract 2007; 24: 34-40. 9. Burns T, Cohen A. Item-of-service payments for general practitioner care of severely mentally ill persons. Br J Gen Pract $1998 ; 48: 1415-6$.

10. Kilbourne AM, Welsh D. Quality of care for patients with and without mental disorders. J Gen Intern Med 2008; 23:1628-33.

11. Hippisley-Cox J, Parker C, Coupland C, Vinogradova Y. Inequalities in the primary care of patients with coronary heart disease and serious mental health problems: a crosssectional study. Heart 2007; 93:1256-62.

12. Author's own, 2009.

13. Glasgow RE, Lichtenstein E, Marcus AC. Why don't we see more of translation of health promotion research to practice Am J of Public Health 2003; 93:1261-1267. 
14. LaFrond A, Brown L, MacIntyre K. Mapping capacity in the health sector: a conceptual framework. Int J Health Plann Manage 2002; 17: 3-22.

15. Bell Woodard G, McLean S, Green K, Moore M, Williams L. Health Promotion Capacity Checklists. A Workbook for Individual, Organizational and Environmental Assessment, University of Saskatchewan, Saskatchewan; 2004

16. Crisp BR, Swerissen H, Duckett SJ. Four approaches to capacity building in health: consequences for measurmment and accountability. Health Promot Int 2000; 15: 99106.

17. Anderson D, Plotnikoff R, Raine K, Barrett L.. Development of measures of individual leadership for health promotion. Leadersh Health Serv 2005; 18: i-xii.

18. JonesJ, Barry M.. Developing a scale to measure syergy in health promotion partnerships. Glob Health Promot 2005; 18: 36-44.

19. PlotnikoffR, Anderson D, Raine K, Cook K, Barrett L, Prodaniuk T. ) Scale development of individual and organisation infrasturcture for heart health promotion in regional health authorities. Health Educ J 2005; 64: 256-269.

20. Anderson D, Plotnikoff R, Raine K, Cook K, Smith C, Barrett L. Towards the development of scales to measure "will" to promote heart heath within organizations in Canada. Health Promot Int 2004; 10: 471-481.

21. Griffin S, Reininger B, Parra-Medina D, Evans A, Sanderson M, Vincent M. Development of multidimensional scales to measure key leaders perceptions of community capacity and organizational capacity for teen pregnancy prevention. Fam Community Health 2005; 28: 307-319. 
22. Mittelmark M, Fosse E, Jones C, et al. Mapping European capacity to engage in health promotion at the national level. Promot Educ 2005;12:33-39.

23. Woo Nam E, \&Engelhardt K. Health promotion capacity mapping. Health Promot Int 2007; 23: 155-162.

24. Bachner YG, Castel H, Kushnir T. Examination of a modified version of the psychological medical inventory among medical students. Med Teach 2008;30:94-96.

25. Kaner EF, Heather N, McAvoy BR. Intervention for excessive alcohol consumption in primary health care: attitudes and practices of English general practitioners. Alcohol Alcohol 1999:34:559-566.

26. Steptoe A, Doherty S, Kendrick T, et al. Attitudes to cardiovascular health promotion among GPs and practice nurses. Fam Pract 1999;16:158-163.

27. IBM Corp. IBM SPSS Statistics for Windows, Version 21.0. Armonk, NY: IBM Corp; Released 2012.

28. Hobart JC, Lamping DL, Freeman JA, et al. Evidenced-based measurement: which disability scale for neurologic rehabilitation? Neurology 2001;57:639-44.

29. George D, Mallery, P. SPSS for Windows step by step: A simple guide and reference. 11.0 update (4 $4^{\text {th }}$ ed.). Boston: Allyn \& Bacon; 2003.

30. Tabachnick BG, Fidell LS. Using multivariate statistics, fifth edition. Boston: Allyn \& Bacon; 2007.

31. Ebbesen L, Heath S, Naylor P, Anderson D. Issues in measuring health promotion capacity in Canada: A multi-province perspective. Health Promot Int 2004;19:85-94. 
Table 1.

Participants' demographic characteristics

\begin{tabular}{|c|c|}
\hline Demographics & $\begin{array}{c}\text { Total Sample } \\
(n=785) \\
\end{array}$ \\
\hline \multicolumn{2}{|l|}{ Gender } \\
\hline Female & $607(77.3 \%)$ \\
\hline Male & $167(21.3 \%)$ \\
\hline Missing data & $11(1.4 \%)$ \\
\hline \multicolumn{2}{|l|}{ Mean age (SD) } \\
\hline All participants & $41.92(11.18)$ \\
\hline Female & $41.55(11.26)$ \\
\hline Male & $43.28(10.88)$ \\
\hline \multicolumn{2}{|l|}{ Education level } \\
\hline University degree & $623(80.9 \%)$ \\
\hline Technical diploma, year 12 or below & $147(19 \%)$ \\
\hline \multicolumn{2}{|c|}{$\begin{array}{l}\text { Education or supervision received in health } \\
\text { promotion ( }>40 \text { hours) }\end{array}$} \\
\hline More than 40 hours & $321(41.4 \%)$ \\
\hline 40 hours or less & $266(34.4 \%)$ \\
\hline None & $83(10.7 \%)$ \\
\hline Don't know/Can't remember & $105(13.3 \%)$ \\
\hline \multicolumn{2}{|l|}{ Current discipline } \\
\hline Medical & $85(11.0 \%)$ \\
\hline Nursing & $340(43.9 \%)$ \\
\hline Allied health & $198(25.6 \%)$ \\
\hline Health worker & $14(1.8 \%)$ \\
\hline Health promotion officer & $13(1.7 \%)$ \\
\hline Other & $124(16 \%)$ \\
\hline \multicolumn{2}{|l|}{ Current employment status } \\
\hline Full-time & $566(73.4 \%)$ \\
\hline Part-time & $166(21.5 \%)$ \\
\hline Casual employee & $19(2.5 \%)$ \\
\hline Self-employed/business owner & $19(2.5 \%)$ \\
\hline Volunteer & $1(0.1 \%)$ \\
\hline \multicolumn{2}{|c|}{$\begin{array}{l}\text { Average consultations with people with SMI per } \\
\text { month }\end{array}$} \\
\hline $0-4$ & $244(33.6 \%)$ \\
\hline $5-20$ & $224(30.8 \%)$ \\
\hline$>20$ & $258(35.5 \%)$ \\
\hline
\end{tabular}


Table 2. Oblique rotated principal component loadings and communality estimates for the 22-item Promoting Health in SMI Survey

\begin{tabular}{lllllll}
\hline Items & $\mathbf{1}$ & $\mathbf{2}$ & $\mathbf{3}$ & $\mathbf{4}$ & $\mathbf{5}$ & $\boldsymbol{h}^{2 a}$ \\
\hline
\end{tabular}

Beliefs about Behaviour Change

It is possible to persuade people with SMI to

modify their lifestyle by reducing their:

- Overweight/obesity

- Drug and alcohol use/abuse

$\begin{array}{cccccc}\mathbf{. 9 3}^{\mathbf{b}} & .11 & .20 & .11 & .05 & .92 \\ \mathbf{. 9 1} & .07 & .19 & .10 & .04 & .89 \\ \mathbf{. 9 1} & .09 & .14 & .09 & .08 & .87 \\ \mathbf{. 9 0} & .09 & .22 & .13 & .07 & .89 \\ \mathbf{. 8 8} & .09 & .23 & .10 & .07 & .85\end{array}$

- Poor oral health/hygiene

.88

.85

\section{Intention to Promote Health}

In these circumstances, rate your intention to advise the person about each of the following factors:

- Alcohol and other drugs

.09

- Overweight/obesity

.14

.81

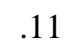

.14

.05

.71

- Sexual health

.09

.79

.04

.13

.16

- Chronic disease

.03

- Quality use of medicine

$-.06$

.76

.06

.05

.13

- $\quad$ Smoking

- Oral health

.08

.70

.16

.22

\section{Effectiveness of Health Promotion}

To what extent do you agree that it is effective to counsel people with SMI in the following areas:

- Quality use of medicine

$$
.10
$$

.88

- Sexual and reproductive health

- $\quad$ Healthy lifestyles

\section{Health Promotion Skills}

To what extent do you agree with the

following regarding your training and skills?

- I feel properly trained to give health promotion advice to people with SMI 


\begin{tabular}{|c|c|c|c|c|c|c|}
\hline Items & 1 & 2 & 3 & 4 & 5 & $h^{2 a}$ \\
\hline $\begin{array}{l}\text { I feel properly trained to give health } \\
\text { promotion advice to the general } \\
\text { population }\end{array}$ & -.07 & .11 & .08 & .73 & .16 & .74 \\
\hline $\begin{array}{l}\text { It is not difficult to counsel people with } \\
\text { SMI about an alternative lifestyle to } \\
\text { promote their health }\end{array}$ & .24 & .12 & -.00 & .66 & -.03 & .50 \\
\hline \multicolumn{7}{|l|}{$\begin{array}{l}\text { Health Promoting Norms } \\
\text { To what extent do you agree with the } \\
\text { following statements regarding health } \\
\text { promotion with people with SMI: }\end{array}$} \\
\hline $\begin{array}{l}\text { People who are important to me think that } \\
\text { I should include health promotion in my } \\
\text { practice }\end{array}$ & .10 & .19 & .01 & .14 & .80 & .70 \\
\hline $\begin{array}{l}\text { The professional organisation I respect } \\
\text { most would approve of including health } \\
\text { promotion in my practice }\end{array}$ & .08 & .13 & .11 & .15 & .74 & .60 \\
\hline $\begin{array}{l}\text { - Most professionals include health } \\
\text { promotion in their practice }\end{array}$ & .03 & .19 & .03 & .03 & .67 & .48 \\
\hline Percentage variance $(72.59 \%)$ & $33.44^{\mathrm{c}}$ & 16.79 & 9.14 & 7.10 & 6.13 & \\
\hline
\end{tabular}

${ }^{\mathrm{a}} \mathrm{h}^{2}=$ communality estimates

${ }^{\mathrm{b}}$ factor loadings above 0.40 are in boldface

${ }^{c}$ percentage variance accounted for by each component 
Table 3. Spearman's correlations between the subscales of the Capacity in Health Promotion Survey

\begin{tabular}{|c|c|c|c|c|c|}
\hline & $\begin{array}{c}\text { Behaviour } \\
\text { Change to } \\
\text { Promote Health }\end{array}$ & $\begin{array}{l}\text { Intention to } \\
\text { Promote } \\
\text { Health }\end{array}$ & $\begin{array}{c}\text { Health Promotion } \\
\text { Skills }\end{array}$ & $\begin{array}{l}\text { Effectiveness } \\
\text { of Health } \\
\text { Promotion }\end{array}$ & $\begin{array}{l}\text { Health } \\
\text { Promoting } \\
\text { Norms }\end{array}$ \\
\hline $\begin{array}{l}\text { Beliefs about } \\
\text { Behaviour Change }\end{array}$ & 1.00 & & & & \\
\hline $\begin{array}{l}\text { Intention to } \\
\text { Promote Health }\end{array}$ & $.22^{* * * 1}$ & 1.00 & & & \\
\hline $\begin{array}{l}\text { Health Promotion } \\
\text { Skills }\end{array}$ & $.31^{* * *}$ & $.33^{* * *}$ & 1.00 & & \\
\hline $\begin{array}{l}\text { Effectiveness of } \\
\text { Health Promotion }\end{array}$ & $.48^{* * *}$ & $.27^{* * *}$ & $.24^{* * *}$ & 1.00 & \\
\hline $\begin{array}{l}\text { Health Promoting } \\
\text { Norms }\end{array}$ & $.16^{* * * *}$ & $.34^{* * *}$ & $.30^{* * * *}$ & $.19^{* * *}$ & 1.00 \\
\hline
\end{tabular}

T*** $\mathrm{p}<.001$ 
Table 4. Item reliability and validity estimates for the Promoting Health in SMI Survey subscales

\begin{tabular}{lccccc}
\hline Subscales & No. of items & $\begin{array}{c}\text { Internal } \\
\text { consistency } \\
\text { (Cronbach's } \\
\text { alpha) }\end{array}$ & $\begin{array}{c}\text { Corrected item- } \\
\text { total correlations }\end{array}$ & $\begin{array}{c}\text { Range of inter- } \\
\text { item correlations }\end{array}$ & $\begin{array}{c}\text { Range of } \\
\text { item- } \\
\text { discriminant } \\
\text { validity }\end{array}$ \\
\hline $\begin{array}{l}\text { Beliefs about } \\
\text { Behaviour } \\
\text { Change }\end{array}$ & 5 & .97 & $.88-.94$ & $.79-.90$ & $.07-.48$ \\
$\begin{array}{l}\text { Intention to } \\
\text { Promote Health }\end{array}$ & 7 & .90 & $.63-.76$ & $.40-.71$ & $.06-.34$ \\
$\begin{array}{l}\text { Health } \\
\text { Promotion Skills }\end{array}$ & 4 & .81 & $.49-.77$ & $.26-.72$ & $.05-.33$ \\
$\begin{array}{l}\text { Effectiveness of } \\
\text { Health } \\
\text { Promotion }\end{array}$ & 3 & .94 & $.86-.89$ & $.82-.86$ & $.10-.48$ \\
$\begin{array}{l}\text { Health } \\
\text { Promoting }\end{array}$ & 3 & & & & \\
Norms & & .65 & $.40-.54$ & $.28-.49$ & $.07-.34$ \\
\hline
\end{tabular}

